\title{
Body Mass Index is Negatively Associated with Endometrial Cancer Stage, Regardless of Subtype and Menopausal Status
}

\author{
Yifei Gao ${ }^{*}$, Xujing Dai1 ${ }^{*}$, Arier C Lee ${ }^{2}$, Michelle R Wise ${ }^{3}$, Fang Shen ${ }^{\circledR}{ }^{\bowtie}$, Qi Chen $^{1,3}{ }^{凶}$ \\ 1. The Hospital of Obstetrics \& Gynaecology, Fudan University, China \\ 2. Section of Epidemiology and Biostatistics, School of Population Health, The University of Auckland, New Zealand \\ 3. Department of Obstetrics \& Gynaecology, FMHS, University of Auckland, New Zealand \\ *YF Gao and XJ Dai equally contributed to this study. \\ $\square$ Corresponding authors: Dr. Fang Shen or Prof. Q Chen, 419 Fangxie Road, Shanghai, China, The Hospital of Obstetrics \& Gynaecology, Fudan University, \\ China. Email: q.chen@auckland.ac.nz or: shenfang1213@126.com; Phone: 86-13611691734 \\ (c) Ivyspring International Publisher. This is an open access article distributed under the terms of the Creative Commons Attribution (CC BY-NC) license \\ (https://creativecommons.org/licenses/by-nc/4.0/). See http://ivyspring.com/terms for full terms and conditions.
}

Received: 2017.05.22; Accepted: 2017.07.10; Published: 2018.11.25

\begin{abstract}
Objective: Obesity is one of the common risk factors for developing of endometrial cancer and is negatively associated with its survival, although this result is controversial. Endometrial cancer stages range from stage I, which has better clinical outcomes to stage IV, which has poorer clinical outcomes. Endometrial cancer traditionally divides into type 1 and type 2 dependent on histology which has different clinical outcomes. In this study we investigated whether obesity is associated with the stages of endometrial cancer taking into account subtypes of cancer and menopausal status.

Methods: Data on 1,104 women with endometrial cancer were retrospectively collected from the largest women's hospital in China and analysed. Data included age at diagnosis, body mass index (BMI), histology of cancer and menopausal status.

Results: The BMI in patients with stage I endometrial cancer was significantly higher than that in patients with stage II or III or IV $(p=0.0001)$. However, there was no statistical difference in BMI between patients with stage II, and stage III endometrial cancer. This negative association was persisted with type 1 and type 2 endometrial cancer $(p=0.1989)$ and premenopausal and post-menopausal status $(p=0.4342)$. In addition, the proportion of over-weight or obese women in typel endometrial cancer with stage I was not different to type 2 endometrial cancer with stage $I$.

Conclusion: Our data demonstrate that BMI is negatively associated with endometrial cancer in early stage regardless of subtypes of cancer, menopausal status and obesity may be also a potential risk factor for developing type 2 endometrial cancer.
\end{abstract}

Key words: endometrial cancer, BMI, subtype, menopause

\section{Introduction}

Endometrial cancer is the most common gynaecological cancer in developed countries, and the fourth most common cancer among women in the United States [1]. In 2014, it occurred in 320,000 women and caused 76,000 deaths worldwide [2]. Over time, there has been a significant increase in the number of Chinese women diagnosed with endometrial cancer [3]. Parity, body mass index (BMI), physical activity and diet may explain up to $80 \%$ of the risk of endometrial cancer [4].

Endometrial cancer survival is strongly associated with stage, myometrial invasion and histological type, including cancer cell differentiation [5]. Endometrial cancer stages range from stage I, which the cancer cells have not invaded beyond the lining of the uterus to stage IV, which the cancer cells have spread to distant organs, such as the liver. In general, lower stage cancers are less aggressive and require 
less treatment than do higher stage cancers and have better clinical outcomes. Studies have suggested that BMI is negatively associated with endometrial cancer survival $[6,7]$, although the profiling of these results in this association is controversial $[7,8]$. Other study also reported that BMI has no independent prognostic impact on survival [9]. This could be because the effect of BMI, including the weight changes during adulthood on the risk factors of developing endometrial cancer and clinical outcomes across different ethnic groups [10]. In addition, the World Health Organisation (WHO) classification of BMI for Asians is different from that for Caucasians, as is the proportion of population in each category [11].

Endometrial cancer is traditionally divided into type 1 and type 2 . The majority of endometrial cancer $(80-85 \%)$ is type 1 , which traditionally is hormone sensitive, occurs at early stage and has better clinical outcomes. Type 2, on the other hand, is thought to be estrogen independent, tends to be higher grade and has poorer clinical outcomes.

Studies have suggested that over 70\% women with type 1 endometrial cancer are obese $[12,13]$, and that $90 \%$ of Caucasian women with endometrial cancer are over 50 years of age, with a median age of 63 years (Endometrial cancer: ESMO Clinical Practice Guidelines for diagnosis, treatment and follow-up; European Society for Medical Oncology, 2013). These studies suggest that the association of BMI and survival may also depend on the subtypes of cancer and/or menopausal status. However, a number of recent studies indicated that type 2 endometrial cancer may not be completely estrogen-independent and has similar pathogenesis with type 1 [14-16]. Moreover, $42 \%$ of Chinese women with endometrial cancer in our recent study were pre-menopausal, regardless of subtype [17]. This prompted us to question whether the association of obesity and survival is in fact same in the different types of endometrial cancer as well.

$\mathrm{BMI}$ is positively correlated with the incidence of endometrial cancer and negatively associated with survival of endometrial cancer. Whether the negative association of BMI and survival of endometrial cancer is because of the association of BMI and the stages of endometrial cancer has not been investigated yet. Therefore the objective of this retrospective study was to investigate the association between BMI and endometrial cancer stages in Chinese women, taking into account histologic type and menopausal status.

\section{Materials and Methods}

This study was approved by the Ethics Committee of The Hospital of Obstetrics \& Gynaecology, Fudan University, China.

\section{Study participants}

This was a retrospective cohort study of 1,104 women with endometrial cancer admitted to The Hospital of Obstetrics and Gynaecology, Fudan University, China from January 1, 2011 to December 31, 2014. This is the largest Obstetrics \& Gynaecology university teaching hospital, serving a diverse urban and rural population in Shanghai, the largest city in China with a population of 20 million. Data on all patients with a primary diagnosis of endometrial cancer were collected from electronic medical records. Clinical data included age at diagnosis, self-reported age at menopause, BMI, and subtypes and stages of cancer.

Weight and height at time of diagnosis were measured and BMI calculated and classified according to the ethnicity-specific WHO classification for Asian/Indian women: underweight (under 18.4 $\left.\mathrm{kg} / \mathrm{m}^{2}\right)$, normal weight $\left(18.5-22.99 \mathrm{~kg} / \mathrm{m}^{2}\right)$, overweight $\left(23-27.49 \mathrm{~kg} / \mathrm{m}^{2}\right)$, and obese (over 27.50 $\mathrm{kg} / \mathrm{m}^{2}$ ) [11]. The classification of type 1 and type 2 endometrial cancer was determined by pathological examination of biopsies, including cancer histologic subtype and grade. We classified endometrioid and adenosquamous carcinoma with grade 1 and 2 as type 1 endometrial cancer. Clear-cell, serous, mucinous carcinoma and grade 3 endometrioid carcinoma were classified as type 2 endometrial cancers, according to the classification of the International Federation of Gynaecology and Obstetrics (FIGO)[18]. The stage of endometrial cancer was also classified by FIGO guideline [19].

\section{Statistical analysis}

The association between BMI and stages of endometrial cancer, adjusting for age, menopausal status and the subtypes of endometrial cancer, was analysed using multiple linear regression using SAS software version 9.4 (SAS Institute Inc., Cary, NC, USA). The statistical difference in the proportion of overweight or obese between type 1 and type 2 endometrial cancer was assessed by Fisher's exact test using Prison software version 7. Two side $P$ value of less than 0.05 was considered statistically significant.

\section{Result}

\section{Clinical characteristics of the study population}

The clinical characteristics of study participants are summarised in Table 1 . The median age of patients at diagnosis was 54 (range 26-88) years old. Of 1,104 patients, $483(43.7 \%)$ patients were diagnosed before menopause and $713(65 \%)$ patients were overweight or obese. Of 1,104 patients, 872 (79\%) were diagnosed with type 1 endometrial cancer. 
Table 1. Clinical characteristics of the study population

\begin{tabular}{ll}
\hline & $\begin{array}{l}\text { Women with endometrial } \\
\text { cancer (n=1,104) }\end{array}$ \\
\hline Age at diagnosis (years, median/range) & $54(26-88)$ \\
Type 1 (number, \%) & $872(79 \%)$ \\
Type 2 (number, \%) & $232(21 \%)$ \\
Premenopause (number, \%) & $483(44 \%)$ \\
Postmenopause (number, \%) & $621(56 \%)$ \\
Histological stage & \\
Stage I (number, \%) & $851(77 \%)$ \\
Stage II (number, \%) & $115(10 \%)$ \\
Stage III (number, \%) & $119(11 \%)$ \\
Stage IV (number, \%) & $19(2 \%)$ \\
\hline
\end{tabular}

\section{BMI is associated with the stages of endometrial cancer regardless of subtypes of endometrial cancer and menopausal status}

Overall, the median BMI in patients with stage I or stage II or stage III or stage IV was 24.01 (range from 15.2 to 40.2$) \mathrm{kg} / \mathrm{m}^{2}$ or 23.44 (range from 13.6 to 37.3 ) $\mathrm{kg} / \mathrm{m}^{2}$ or 23.43 (range from 16 to 32.4 ) $\mathrm{kg} / \mathrm{m}^{2}$ or 23.9 (range from 19.1 to 28.9 ) $\mathrm{kg} / \mathrm{m}^{2}$, respectively (Table 2).

We then divided the patients into type 1 and type 2 endometrial cancer (two groups) to investigate the association between BMI and stages of cancer (Table 3). In type 1 endometrial cancer, the median BMI in patients with stage I or stage II or stage III or stage IV was 24.01 (range from 15.2 to 40.2 ) $\mathrm{kg} / \mathrm{m}^{2}$ or 23.44 (range from 17.7 to 37.3 ) $\mathrm{kg} / \mathrm{m}^{2}$ or 23.43 (range from 16.6 to 32.4 ) $\mathrm{kg} / \mathrm{m}^{2}, 20.83$ (range from 19.1 to 22.6) $\mathrm{kg} / \mathrm{m}^{2}$, respectively.

In type 2 endometrial cancer, the median BMI in patients with stage I or stage II or stage III or stage IV was 24.03 (range from 17.7 to 40.2 ) $\mathrm{kg} / \mathrm{m}^{2}$ or 22.89 (range from 13.6 to 34.3 ) $\mathrm{kg} / \mathrm{m}^{2}$ or 23.44 (range from 16 to 30.8$) \mathrm{kg} / \mathrm{m}^{2}, 23.44$ (range from 19.5 to 28.9 ) $\mathrm{kg} / \mathrm{m}^{2}$, respectively (Table 3 ).

We further divided the patients into premenopausal and postmenopausal groups (Table 4). In premenopausal patients, the median BMI in patients with stage I or stage II or stage III or stage IV was 23.71 (range from 17.2 to 40.2 ) $\mathrm{kg} / \mathrm{m}^{2}$ or 22.76 (range from 13.6 to 37.3 ) $\mathrm{kg} / \mathrm{m}^{2}$ or 22.37 (range from 16.6 to $32.4) \mathrm{kg} / \mathrm{m}^{2}, 23.68$ (range from 21.4 to 28.9 ) $\mathrm{kg} / \mathrm{m}^{2}$, respectively. In postmenopausal patients, the median BMI in patients with stage I or stage II or stage III or stage IV was 24.17 (range from 15.2 to 40 ) $\mathrm{kg} / \mathrm{m}^{2}$ or 23.44 (range from 16.1 to 34.3 ) $\mathrm{kg} / \mathrm{m}^{2}$ or 23.83 (range from 16.4 to 30.8 ) $\mathrm{kg} / \mathrm{m}^{2}$ or 22.45 (range from 19.1 to $25.0 \mathrm{~kg} / 2) \mathrm{kg} / \mathrm{m}^{2}$, respectively.

BMI was then analysed using multiple linear regression analysis with type, stage and menopausal status and their interactions as explanatory variables. The results showed that there was no statistically significant difference in BMI between subtypes in endometrial cancer $(p=0.5069)$. There was also no statistically significant difference in BMI between premenopausal women and postmenopausal patients (Table 5, $\mathrm{p}=0.9071$ ), and this was consistent for different stages of endometrial cancer (menopausal status and stage interaction $\mathrm{p}=0.4342$ ). There was a highly statistically significant difference in BMI between patients with different stages (Table 5, $\mathrm{p}<.0001)$, and this difference was consistent between different subtypes of endometrial cancer (stage and type interaction $\mathrm{p}=0.1989$ ) and menopausal status (stage and menopausal interaction $\mathrm{p}=0.4342$ ). The estimated mean BMI using least square means from the multiple linear regression analysis was presented in Table 5.

Table 2. Overall BMI distribution among the different stages of endometrial cancer

\begin{tabular}{ll}
\hline & BMI (median, range) $\left.\mathbf{( k g} / \mathbf{m}^{2}\right)$ \\
\hline Stage I $(\mathrm{n}=851)$ & $24.01(15.2-40.1)$ \\
Stage II $(\mathrm{n}=115)$ & $23.44(13.6-37.3)$ \\
Stage III $(\mathrm{n}=119)$ & $23.43(16-32.4)$ \\
Stage IV $(\mathrm{n}=19)$ & $22.61(19.1-28.9)$ \\
\hline
\end{tabular}

Table 3. The BMI distribution among the different stages of endometrial cancer according to the subtypes of endometrial cancer

\begin{tabular}{lll}
\hline & $\begin{array}{l}\text { Type } \mathbf{1}(\mathbf{n}=\mathbf{8 7 2}) \\
\text { BMI (median, range) }\left(\mathbf{k g} / \mathbf{m}^{2}\right)\end{array}$ & $\begin{array}{l}\text { Type } \mathbf{2}(\mathbf{n}=\mathbf{2 3 2}) \\
\text { BMI }\left(\mathbf{m e d i a n}, \text { range) } \mathbf{( k g} / \mathbf{m}^{2}\right)\end{array}$ \\
\hline Stage I & $24.01(15.2-40.2)$ & $24.03(17.7-40)$ \\
Stage II & $23.44(17.7-37.3)$ & $22.89(13.6-34.3)$ \\
Stage III & $23.43(16.65-32.4)$ & $23.44(16-30.8)$ \\
Stage IV & $20.83(19.1-22.6)$ & $23.44(19.5-28.96)$ \\
\hline
\end{tabular}

Table 4. The BMI distribution among the different stages of endometrial cancer according to menopausal status

\begin{tabular}{lll}
\hline & $\begin{array}{l}\text { Premenopause }(\mathbf{n}=\mathbf{4 8 3}) \\
\text { BMI (median, range) }\left(\mathbf{k g} / \mathbf{m}^{2}\right)\end{array}$ & $\begin{array}{l}\text { Post menopause }(\mathbf{n}=621) \\
\text { BMI }(\text { median, range })\left(\mathbf{k g} / \mathbf{m}^{2}\right)\end{array}$ \\
\hline Stage I & $23.71(17.2-40.2)$ & $24.17(15.2-40)$ \\
Stage II & $22.76(13.6-37.3)$ & $23.44(16.1-34.3)$ \\
Stage III & $22.37(16.6-32.4)$ & $23.83(16.4-30.8)$ \\
Stage IV & $23.68(21.4-28.9)$ & $22.45(19.1-25.0)$ \\
\hline
\end{tabular}

Table 5. Least square means of BMI by type, stage and menopause status from multiple linear regression

\begin{tabular}{lllll}
\hline & BMI $\left(\mathbf{k g} / \mathbf{m}^{2}\right)$ & $\begin{array}{l}\mathbf{9 5 \%} \text { Confidence Limits } \\
\left(\mathbf{k g} / \mathbf{m}^{2}\right)\end{array}$ & Pr $>$ F \\
\hline Type & & & & \\
Type 1 & 23.19 & 22.31 & 24.06 & 0.5069 \\
Type 2 & 23.56 & 22.87 & 24.25 & \\
Stage & & & & $<.0001$ \\
I & 24.77 & 24.41 & 25.13 & \\
II & 23.21 & 22.44 & 23.97 & \\
III & 22.99 & 22.33 & 23.65 & \\
IV & 22.52 & 20.58 & 24.46 & \\
Menopause & & & & 0.9071 \\
Premenopause & 23.41 & 22.50 & 24.32 & \\
Postmenopause & 23.34 & 22.60 & 24.05 & \\
\hline
\end{tabular}




\section{The proportion of overweight/obese is not different between type 1 and type 2 endometrial cancer}

We further analysed the proportion of overweight or obese women between type 1 and type 2 endometrial cancer based on The WHO classification of BMI for Asian/Indian women (Table 6). In type 1 endometrial cancer, 32\% (274 of 855) patients were normal weight, while $66 \%$ (565 of 855 ) patients were overweight or obese. In type 2 endometrial cancer, $35 \%$ (82 of 235) patients were normal weight, while $61 \%$ (143 of 235) patients were overweight or obese. There was no difference in the proportion of patients who were overweight or obese between type 1 and type 2 endometrial cancer $(\mathrm{p}>0.05)$.

Table 6. The proportion of BMI distribution in women with endometrial cancer according to subtypes

\begin{tabular}{llll}
\hline & Type 1 (n=872) & Type 2 (n=232) & P value \\
\hline Under weight (number, \%) & $16(1.8 \%)$ & $10(4.2 \%)$ & $>0.05$ \\
Normal weight (number, \%) & $274(32 \%)$ & $82(35 \%)$ & $>0.05$ \\
Overweight (number, \%) & $395(46.2 \%)$ & $107(45.5 \%)$ & $>0.05$ \\
Obese (number, \%) & $170(20 \%)$ & $36(15.3 \%)$ & $>0.05$ \\
\hline
\end{tabular}

\section{Discussion}

In this retrospective study with a large sample size of Chinese women, we found that the higher BMI the lower stage of endometrial cancer at diagnosis, which may suggest patients with higher BMI have better clinical outcomes. This negative association persisted after adjusting for age, menopausal status and subtypes of cancer.

Most of the risk factors for developing endometrial cancer involve high levels of estrogens and obesity is associated with excessive levels of estrogen $[20,21]$, indicating obesity increases the risk of developing endometrial cancer. However the association of obesity and endometrial cancer survival is unclear and controversial due to the study populations [6, 9]. In our current study, we found that the median BMI of women diagnosed with stage 1 endometrial cancer was significantly higher than in women diagnosed with stage II or III. Interestingly, we further found that there was no difference in BMI between stage II and stage III cancer, suggesting that this negative relationship is restricted to early stage endometrial cancer. A recent study with small sample size $(n=94)$ reported that patients with the increased body fat were more likely to have stage 1 endometrial cancer [22]. Stage I endometrial cancer normally has the best prognosis, while stage IV commonly has a worse prognosis with a median survival time within nine to ten months [23]. Taken together our result indirectly suggests that patients with higher BMI may have better clinical outcomes. Our current findings are surprising to contrast with a recent systemic review study which suggested that obesity associates higher mortality rate of endometrial cancer in general population [6]. However another study showed that $66 \%$ of survivors of endometrial cancer were over-weight or obese after diagnosis [24], suggesting obesity is negatively associated with survival. The difference between our current study and Arem's study [6] could be due to the ethnicity. In general, the BMI in Asian (Chinese) is smaller than in Caucasian and the association between obesity and risk for developing endometrial cancer vary across ethnicities [10]. In addition, factors such as ages at diagnosis that influence cancer survival also differ from different population. We have previously reported that ages at diagnosis of endometrial cancer in Chinese population is significantly younger than Caucasians [17].

Over $70 \%$ endometrial cancer is often detected at stage I (Stage Breakdown by CCG, 2014) and over 70\% of women with type I endometrial cancer are obese $[12,13]$. In our current study we also found that over $77 \%$ endometrial cancers were diagnosed at stage I and only $13 \%$ endometrial cancers were at stage III or IV at diagnosis in Chinese population. Our data is consistent with these studies further suggesting higher BMI is associated with stage I endometrial cancer. The underlying mechanism of this negative association in unknown but it could be associated with abnormal vaginal bleeding. Abnormal vaginal bleeding is one of the main clinical symptoms of endometrial cancer in premenopausal and postmenopausal women and increased unopposed estrogen (E2) which is associated with obesity is associated with abnormal vaginal bleeding.

Endometrial cancer traditionally divides into type 1 and type 2 and menopausal status is one of risk factors for developing endometrial cancer. We then further analysed this negative association taking into account subtypes of cancer and menopausal status. We further found that the negative association between BMI and stage was seen in both type 1 and type 2 cancer as well as seen in both premenopausal women and postmenopausal women, suggesting the negative association between BMI and the stage of endometrial cancer is consistent between different types of endometrial cancer and between women with different menopausal status.

Type 1 endometrial cancer is the prototypical estrogen-dependent cancer. Traditionally, one of the main cited risk factors for developing type I endometrial cancer is obesity [25], and over $70 \%$ of women with type 1 endometrial cancer are over-weight or obese $[12,13]$. Women with type 2 
endometrial cancer are more likely to be older, of normal weight, and multiparous compared to women with type I [26-28]. In our current study, $66 \%$ of women with type 1 endometrial cancer were over-weight or obese, consistent with previous studies; however, $60 \%$ of women with type 2 endometrial cancer were also over-weight or obese. Obesity is associated with excessive levels of estrogen [20, 21], which is a risk factor of developing endometrial cancer, and estrogen may also be involved in the pathogenesis of type 2 endometrial cancer [14-16]. Taken together our data support other findings which suggested obesity may also be involved in developing type 2 endometrial cancer. Our previous study reported that the age at diagnosis of endometrial cancer in Chinese population is approximately 10 years younger than Caucasian reported in the literature, and they are more likely to be pre-menopause [17]. This may support the hypothesis that estrogen may also be involved in the pathogenesis of type 2 endometrial cancer.

We acknowledge that there are some limitations of this study. First the age at menopause was self-reported. Secondly, the number of patients with stage IV was small and future study with large sample size of stage IV of endometrial cancer to confirm our conclusions is necessary.

In conclusion, our data demonstrate that in a population of Chinese women with endometrial cancer, BMI is negatively associated with the stages of endometrial cancer, regardless of the subtypes of endometrial cancer and menopausal status. In addition, the proportion of patients with over-weight or obese in type 1 endometrial cancer is not different with type 2 endometrial cancer. Our data support hypothesis that obesity may be also involved in the pathogenesis of type 2 endometrial cancer. Therefore our study suggests that obese women with endometrial cancer may have better clinical outcomes, regardless of menopausal status, and that clinicians should be aware that obese women may also develop type 2 endometrial cancer.

\section{Acknowledgments}

This study did not receive any specific grant from any funding agency in the public, commercial or not-for-profit sector.

\section{Competing Interests}

The authors have declared that no competing interest exists.

\section{References}

1. Siegel R, Ward E, Brawley O, Jemal A. Cancer statistics, 2011: the impact of eliminating socioeconomic and racial disparities on premature cancer deaths. CA Cancer J Clin. 2011;61(4):212-36.
2. Stewart BW, Wild C. World cancer report. Chapter 1: Cancer Worldwide. Lyon, France2014.

3. Li X, Zheng S, Chen S, Qin F, Lau S, Chen Q. Trends in gynaecological cancers in the largest obstetrics and gynaecology hospital in China from 2003 to 2013. Tumour Biol. 2015;36(7):4961-6.

4. Spurdle AB, Thompson DJ, Ahmed S, Ferguson K, Healey CS, O'Mara T, Walker LC, Montgomery SB, Dermitzakis ET, Fahey P, Montgomery GW, Webb PM, Fasching PA, Beckmann MW, Ekici AB, Hein A, Lambrechts D, Coenegrachts L, Vergote I, Amant F, Salvesen HB, Trovik J, Njolstad TS, Helland H, Scott RJ, Ashton K, Proietto T, Otton G, Tomlinson I, Gorman M, Howarth K, Hodgson S, Garcia-Closas M, Wentzensen N, Yang H, Chanock S, Hall P, Czene K, Liu J, Li J, Shu XO, Zheng W, Long J, Xiang YB, Shah M, Morrison J, Michailidou K, Pharoah PD, Dunning AM, Easton DF. Genome-wide association study identifies a common variant associated with risk of endometrial cancer. Nat Genet. 2011;43(5):451-4.

5. Amant F, Cadron I, Fuso L, Berteloot P, de Jonge E, Jacomen G, Van Robaeys J, Neven P, Moerman P, Vergote I. Endometrial carcinosarcomas have a different prognosis and pattern of spread compared to high-risk epithelial endometrial cancer. Gynecol Oncol. 2005;98(2):274-80.

6. Arem H, Irwin ML. Obesity and endometrial cancer survival: a systematic review. International journal of obesity (2005). 2013;37(5):634-9.

7. McTiernan A, Irwin M, Vongruenigen V. Weight, physical activity, diet, and prognosis in breast and gynecologic cancers. J Clin Oncol. 2010;28(26):4074-80.

8. Fader AN, Arriba LN, Frasure HE, von Gruenigen VE. Endometrial cancer and obesity: epidemiology, biomarkers, prevention and survivorship. Gynecol Oncol. 2009;114(1):121-7.

9. Mauland KK, Trovik J, Wik E, Raeder MB, Njolstad TS, Stefansson IM, Oyan AM, Kalland KH, Bjorge T, Akslen LA, Salvesen HB. High BMI is significantly associated with positive progesterone receptor status and clinico-pathological markers for non-aggressive disease in endometrial cancer. $\mathrm{Br} \mathrm{J}$ Cancer. 2011;104(6):921-6.

10. Park SL, Goodman MT, Zhang Z-F, Kolonel LN, Henderson BE, Setiawan VW. Body Size, Adult BMI Gain and Endometrial Cancer Risk: The Multiethnic Cohort. International journal of cancer Journal international du cancer. 2010;126(2):490-9.

11. Appropriate body-mass index for Asian populations and its implications for policy and intervention strategies. Lancet. 2004;363(9403):157-63.

12. Courneya KS, Karvinen KH, Campbell KL, Pearcey RG, Dundas G, Capstick $\mathrm{V}$, Tonkin KS. Associations among exercise, body weight, and quality of life in a population-based sample of endometrial cancer survivors. Gynecol Oncol. 2005;97(2):422-30.

13. Sorosky JI. Endometrial cancer. Obstet Gynecol. 2008;111(2 Pt 1):436-47.

14. Setiawan VW, Yang HP, Pike MC, McCann SE, Yu H, Xiang YB, Wolk A, Wentzensen N, Weiss NS, Webb PM, van den Brandt PA, van de Vijver K, Thompson PJ, Australian National Endometrial Cancer Study G, Strom BL, Spurdle AB, Soslow RA, Shu XO, Schairer C, Sacerdote C, Rohan TE, Robien K, Risch HA, Ricceri F, Rebbeck TR, Rastogi R, Prescott J, Polidoro S, Park Y, Olson SH, Moysich KB, Miller AB, McCullough ML, Matsuno RK, Magliocco AM, Lurie G, Lu L, Lissowska J, Liang X, Lacey JV, Jr., Kolonel LN, Henderson BE, Hankinson SE, Hakansson N, Goodman MT, Gaudet MM, Garcia-Closas M, Friedenreich CM, Freudenheim JL, Doherty J, De Vivo I, Courneya KS, Cook LS, Chen C, Cerhan JR, Cai H, Brinton LA, Bernstein L, Anderson KE, Anton-Culver H, Schouten LJ, Horn-Ross PL. Type I and II endometrial cancers: have they different risk factors? J Clin Oncol. 2013;31(20):2607-18.

15. Wan J, Gao Y, Zeng K, Yin Y, Zhao M, Wei J, Chen Q. The levels of the sex hormones are not different between type 1 and type 2 endometrial cancer. Sci Rep. 2016;6:39744

16. Shen F, Gao Y, Ding J, Chen Q. Is the positivity of estrogen receptor or progesterone receptor different between type 1 and type 2 endometrial cancer? Oncotarget. 2017;8(1):506-11.

17. Gao Y, Zhao M, Dai X, Tong M, Wei J, Chen Q. The prevalence of endometrial cancer in pre- and postmenopausal Chinese women. Menopause. 2016;23(8):884-7.

18. Bokhman JV. Two pathogenetic types of endometrial carcinoma. Gynecol Oncol. 1983;15(1):10-7.

19. Creasman W. Revised FIGO staging for carcinoma of the endometrium. Int J Gynaecol Obstet. 2009;105(2):109.

20. Hoffman B, Schorge J, Schaffer J, Halvorson LM, Bradshaw K, Cunningham F, Calver LE. Williams Gynecology: Endometrial Cancer 2nd ed.: McGraw-Hill. ; 2012.

21. Soliman P, Lu K. Comprehensive Gynecology: Neoplastic Diseases of the Uterus. 6th ed.: Mosby; 2013.

22. Kerimoglu OS, Pekin A, Yilmaz SA, Yavas G, Beyhekim F, Demirtas AA, Dogan NU, Ilhan TT, Celik C. Effect of the percentage of body fat on surgical, clinical and pathological outcomes in women with endometrial cancer. J Obstet Gynaecol Res. 2015;41(3):449-55.

23. Ang C, Bryant A, Barton DP, Pomel C, Naik R. Exenterative surgery for recurrent gynaecological malignancies. Cochrane Database Syst Rev. 2014(2):CD010449.

24. Basen-Engquist K, Scruggs S, Jhingran A, Bodurka DC, Lu K, Ramondetta L, Hughes D, Carmack Taylor C. Physical activity and obesity in endometrial cancer survivors: associations with pain, fatigue, and physical functioning. Am J Obstet Gynecol. 2009;200(3):288 e1-8. 
25. Felix AS, Weissfeld JL, Stone RA, Bowser R, Chivukula M, Edwards RP, Linkov F. Factors associated with Type I and Type II endometrial cancer. Cancer causes \& control : CCC. 2010;21(11):1851-6.

26. Dunton CJ, Balsara G, McFarland M, Hernandez E. Uterine papillary serous carcinoma: a review. Obstet Gynecol Surv. 1991;46(2):97-102.

27. Fader AN, Starks D, Gehrig PA, Secord AA, Frasure HE, O'Malley DM, Tuller ER, Rose PG, Havrilesky LJ, Moore KN, Huh WK, Axtell AE, Kelley JL, Zanotti KM. An updated clinicopathologic study of early-stage uterine papillary serous carcinoma (UPSC). Gynecol Oncol. 2009;115(2):244-8.

28. Boruta DM, 2nd, Gehrig PA, Fader AN, Olawaiye AB. Management of women with uterine papillary serous cancer: a Society of Gynecologic Oncology (SGO) review. Gynecol Oncol. 2009;115(1):142-53. 